\title{
Concepção de saúde segundo população masculina usuária do SUS.
}

\section{Concepción de la salud de acuerdo con usuario población masculina de SUS.}

\section{Health conception second the male population users of SUS.}

\author{
Fátima FERRETTI ${ }^{1}$ \\ Fernando BEHLING ${ }^{2}$ \\ Emílio Gabriel Ferro SCHNEIDER ${ }^{3}$
}

RESUMO: A saúde é um fenômeno que difere de acordo com aspectos biológicos, culturais, sociais e históricos e o modo como cada ser humano viveu sua vida. Dessa forma, o objetivo deste estudo foi conhecer a concepção de saúde segundo o relato de população masculina usuária do SUS. Para tanto, foram entrevistados 49 homens usuários de um Centro de Saúde da Família de um município do oeste catarinense e a análise dos dados se deu segundo a proposição de Minayo (2004). A concepção de saúde relatada pelos homens esteve centrada em duas categorias, ausência de doenças e conceito ampliado de saúde. Historicamente o homem preocupa-se com sua saúde apenas mediante intercorrências graves. No entanto, parece-nos que há uma mudança de comportamento ocorrendo na população masculina, em que essa preocupação passa a se dar antes da enfermidade surgir, numa perspectiva preventiva. Palavras chaves: Saúde do homem. Formação de conceito. Masculinidade.

\begin{abstract}
Health is a phenomenon that differs according to biological, cultural, social and historical, and how every human being has lived his life. Thus, the aim of this study was to explore the concept of health according to the account of the male users of Health System. To that end, we interviewed 49 male users of a Family Health Center in a city in western Santa Catarina and analysis of data was according to proposition Minayo (2004). The concept of health reported by men was centered in two categories, the absence of diseases and expanded concept of health. Historically man is concerned about his health just by serious complications. However, it seems that there is a change in behavior occurring in the male population, that this concern is to be given before the disease appears, a preventive perspective. 1 Instituição: Universidade Comunitária da Região de Chapecó - UNOCHAPECÓ. Professora e Coordenadora Adjunta do Mestrado em Ciências da Saúde da UNOCHAPECÓ. Doutorado em saúde coletiva pela UNIFESP (2011). Líder do grupo de pesquisa de Envelhecimento Humano e Saúde. email: ferrettifisio@yahoo.com.br 2 Instituião: Universidade Comunitária da região de Chapecó. Bolsista Pet-Saúde Fisioterapia. Área de Ciências da Saúde. Email: fernandobehling@unochapeco.edu.br

3 Instituição: Universidade Comunitária da região de Chapecó. Bolsista Pet-Saúde Medicina. Área de Ciências da Saúde. Email: emiliofs@unochapeco.edu.br
\end{abstract}


Keywords: Men's Health. Concept Formation. Masculinity.

RESUMEN: La salud es un fenómeno que varía de acuerdo a la diversidad biológica, cultural, social e histórica, y como todo ser humano ha vivido su vida. Por lo tanto, el objetivo de este estudio fue explorar el concepto de salud de acuerdo a la cuenta de los usuarios masculinos del sistema unico del salud. Para ello, se entrevistó a 49 hombres usuarios de un Centro de Salud de la Familia en una ciudad en el oeste de Santa Catarina y el análisis de los datos fue de acuerdo a la proposición Minayo (2004). El concepto de salud reportado por los hombres se centraba en dos categorías, la ausencia de enfermedades y el concepto ampliado de salud. Históricamente el hombre se preocupa por su salud sólo por las complicaciones graves. Sin embargo, parece que hay un cambio de comportamiento que ocurre en la población masculina en esta preocupación, le será dado antes de que la enfermedad aparece en un punto de vista preventivo.

Palabras clave: Salud del Hombre. Formación de Concepto. Masculinidad.

\section{INTRODUÇÃO}

Os primeiros estudos acerca da saúde de homens surgiram no final dos anos 1970, nos Estados Unidos, voltados principalmente para os problemas de saúde dessa população. A partir dos anos 1990, a abordagem focalizou as singularidades do processo saúde-doença, a partir de uma perspectiva relacional de gênero e, nos primeiros anos do século XXI, a temática "saúde do homem" passou a ser objeto de vários estudos ${ }^{1}$. Os debates nacionais e internacionais tem evidenciado uma necessidade de se organizar a atenção básica em saúde de acordo com especificidades da população masculina. Nessas discussões, ressaltam-se, pelo menos, duas temáticas que se configuram como desafios para o sistema público de saúde: ações para que segmentos masculinos procurem os serviços de atenção básica em saúde e adequação dos serviços de saúde às demandas dos homens que procuram esses serviços ${ }^{2}$.

Nesse sentido o estudo que ora se apresenta se insere no diálogo referente à primeira temática, pois, considera que um fator determinante para adesão do homem aos programas de saúde pode ser a sua concepção. Discutir saúde implica necessariamente o debate em torno da concepção dessa população sobre esse tema, tendo em vista que a saúde depende de questões culturais, científicas, religiosas e filosóficas que interferem na maneira como este adere aos programas e serviços ofertados pelo sistema.

Conforme Scliar ${ }^{3}$ o conceito de saúde reflete a conjuntura social, econômica, política e cultural. Ou seja, saúde não representa a mesma coisa para todas as pessoas, dependerá da época, do lugar, da classe social. Como destacam Ferretti, Nierotka e Silva ${ }^{4}$ a cultura de um indivíduo pode ser um fator protetor da saúde, ou de risco, e predispor ao adoecimento, dependendo do contexto. É preciso considerar que os aspectos culturais envolvidos na questão da saúde e da doença só podem ser compreendidos em contextos específicos, nesse sentido faz-se necessário conhecer a concepção de saúde da população masculina para adentrar numa análise da questão " saúde do homem". 
O processo de viver com ou sem saúde não se reduz a uma evidência orgânica, natural e objetiva e nem como um estado de equilíbrio, mas está intimamente relacionada às características de cada contexto sociocultural e aos significados que cada indivíduo atribui ao seu processo de viver. A saúde, não pode ser apreendida como um fenômeno abstrato e nem mesmo como algo concreto ou atingível e, sim como um modo de ser e produzir e/ou recriar a vida em sua singularidade e multidimensionalidade. ${ }^{5}$

Nessa perspectiva, é preciso dar voz aos homens para que estes possam relatar sua concepção de saúde e que, por meio destas informações, possamos repensar as estratégias que procuram garantir a adesão do homem aos programas a eles ofertados. Nesse sentido o artigo teve como objetivo conhecer a concepção de saúde segundo relato de população masculina usuária do SUS.

\section{METODOLOGIA}

O estudo realizado foi de caráter qualitativo e exploratório. A população do estudo foi localizada em duas microáreas de abrangência de um Centro de Saúde da Família (CSF) do oeste catarinense e composta por 49 homens, com faixa etária entre 20 a 59 anos de idade, conforme preconiza a Política Nacional de Atenção Integral a Saúde do Homem ${ }^{6}$. Estes homens deveriam estar cadastrados no Sistema de Informação da Atenção Básica (SIAB) e serem usuários do Sistema Único de Saúde.

A Secretaria Municipal de Saúde foi inicialmente contatada para autorizar a realização da pesquisa no CSF e na sequência o projeto foi encaminhado e aprovado pelo Comitê de Ética em Pesquisa da Universidade, sob parecer 262|10.

Os instrumentos de coleta de dados utilizados foram um questionário para identificar o perfil dos homens e uma entrevista com questões norteadoras sobre sua concepção de saúde.

A localização inicial da população foi feita mediante visita domiciliar a família juntamente com a agente comunitária daquele território. Nesse primeiro momento se verificava a presença ou não de homem na família e o melhor horário para localizá-lo no domicílio. Após esse primeiro contato a coleta foi agendada nos finais de semana, de acordo com a disponibilidade de cada um, em função de que, a maioria tinha trabalho formal. Primeiramente foram apresentados os objetivos e finalidades da pesquisa e aqueles que aceitaram participar do estudo, assinaram o termo de consentimento livre e esclarecido. Nesse mesmo dia era aplicado um questionário para conhecer o perfil dos sujeitos e em seguida era realizada a entrevista, a qual foi gravada em meio digital e transcrita na íntegra. Um segundo encontro foi realizado para validar a entrevista, onde o sujeito ouvia a transcrição da entrevista, com oportunidade de complementar ou suprimir informações, quando julgava necessário.

Os dados qualitativos foram analisados de acordo com a proposição de Minayo $^{7}$ que preconiza os seguintes passos: Primeiramente a ordenação dos dados que é a etapa de transcrição das observações, releitura do material e organização dos relatos, compondo um corpo teórico, depois a classificação dos dados composto pelo processo de leitura exaustiva e repetida dos textos, 
constituição de um corpus de comunicação, leitura transversal de cada corpo como recorte de unidade de registro, enxugamento dos dados mais relevantes e por fim a análise final e elaboração das categorias analíticas que é a fase em que se levam em conta os objetivos da pesquisa e os temas que emergem das observações e se faz articulação dos dados com o referencial teórico definindo-se as categorias analíticas.

\section{RESULTADOS E DISCUSSÕES}

Nesta pesquisa foram entrevistados 49 homens. Quanto ao perfil, 33 (trinta e três) homens eram casados; 18 (dezoito) possuíam ensino médio e 10 (dez) haviam concluído o ensino superior; 46 (quarenta e três) tinham emprego formal; 31 (trinta e um) possuíam renda maior que três salários mínimos e todos eram usuários do SUS.

Após transcrição das entrevistas, o conteúdo oral sofreu análise de conteúdo e algumas categorias analíticas emergiram quanto à concepção de saúde dos homens: 1) Ausência de doenças e 2) Conceito ampliado de saúde.

\section{1) Categoria: Saúde é a ausência de doenças.}

A procura de homens pelo atendimento de nível básico à saúde é inferior a das mulheres, sendo esse um dos vários fatores que podem ocasionar a morte mais precoce dos homens. Eles sofrem mais de condições graves e crônicas de saúde do que as mulheres e se preocupam menos com o cuidado próprio $^{8}$. Essa baixa adesão ou procura dos homens pelos serviços de saúde tem forte relação com a questão do gênero e sua concepção de saúde, o que o leva a buscar os serviços apenas quando está enfermo.

O homem, de maneira geral, é educado para ser uma pessoa forte e que protege o grupo familiar. Adoecer, nessa situação, significa reconhecer uma limitação, se configura como um sinal de fraqueza ${ }^{9}$. O homem associa o conceito de saúde à ausência de doença, pois, estar enfermo é carecer de cuidados, depender de alguém e mostrar-se frágil, o que não corresponde a figura do masculino construída histórica e culturalmente.

Essa compreensão é ilustrada pelas falas de vários homens, como:

"A saúde é não ficar doente, o homem precisa estar forte" (Sujeito 23, 59 anos); "Saúde é você estar bem, sem ter nenhuma doença. É você estar bem para trabalhar e viver". (sujeito 32). E ainda: "Sei lá, eu dificilmente fico doente, eu não fico doente..". (Sujeito 6, 33 anos); "Para mim saúde é você poder viver sem doença nenhuma..". (Sujeito 7, 59 anos).

Machim $^{10}$ afirma para o homem é importante negar a existência de dor ou sofrimento, de vulnerabilidades, para reforçar a ideia de força do masculino demarcando a diferenciação com o feminino, e, nesse sentido manter-se saudável passa pela perspectiva de negar qualquer tipo de fraqueza, sofrimento ou enfermidade, ideia reforçada pelo relato de outro sujeito: 
"Saúde para mim é não ficar doente, me preocupo muito, pois, tenho problemas nas pernas e problemas de circulação, vou fazer o que aí, fico fraco assim...". (Sujeito 23, 59 anos).

O entendimento de que o conceito de saúde está associado apenas à ausência de doença é um enfoque reducionista, pois, o processo de viver com ou sem saúde não pode ser reduzido a uma dimensão unicamente orgânica e objetiva, precisa levar em conta a individualidade e características socioculturais de cada indivíduo 5 .

Ainda que, observamos a influência da masculinidade no que se refere ao conceito de saúde, não podemos descartar outras concepções em que essa ideia de saúde como ausência de doenças aparece permeada por outros fatores, como evidenciam os relatos:

"Saúde é a pessoa viver sem doença, sem problemas, viver bem, não se estressa [...]". (Sujeito 10, 32 anos). "Saúde para mim é não ser doente, é viver bem e não ter preocupação com o corpo e com a cabeça". (Sujeito 31, 43 anos).

Aparece evidenciado nas falas dos homens que participaram desse estudo, um dilema no que tange ao conceito de saúde. Se, por um lado, ela é compreendida por um grupo de forma reducionista, por outro, como está destacado na segunda categoria, é concebido por alguns como algo complexo e amplo.

\section{Categoria 2: Conceito ampliado de saúde}

Sabe-se que o processo saúde/doença é socialmente determinado pelo comportamento do indivíduo e, a construção histórica e cultural do gênero masculino pode dificultar a adoção de práticas de auto cuidado, pois, o imaginário social vê o homem como um ser invulnerável o que, de certa forma, acaba contribuindo para que ele se cuide menos e se exponha mais a situações de risco ${ }^{2}$. Porém no que tange a população do estudo alguns homens evidenciaram a superação da compreensão desse conceito mais reducionista e, relataram uma concepção de saúde mais ampliada, como mencionado a seguir:

"Saúde é tudo, as pessoas deveriam valorizar mais a saúde, pois sem saúde não é nada, tem que ter uma boa alimentação, caminhar, fazer exercícios físicos, no geral saúde é tudo, nossa vida". (Sujeito 08, 30 anos). "É estar bem tanto fisicamente quanto mentalmente". (Sujeito 26, 54 anos).

Outros verbalizaram um conceito de saúde vinculado aos determinantes de saúde-doença ${ }^{11}$, conforme evidenciado:

"Acho que tem que ter uma boa alimentação, caminhar, comer bem, viver saudável, com a família". (Sujeito 2, 30 anos). "Para ter saúde eu acho que precisa ter uma boa alimentação, praticar exercícios, ingerir frutas, verduras, viver bem com sua casa ... Acho que começa por aí ". (Sujeito 04, 33 anos). "Saúde é pode viver bem, sem se preocupar, para ter uma boa saúde tem que se alimentar bem, ter higiene, caminhar bastante, dançar". (Sujeito 09, 44 anos).

Esses relatos evidenciam, em parte, o que está posto na Lei 8.080, que tem orientado a estruturação 
do sistema de saúde brasileiro e, que destaca alguns fatores determinantes e condicionantes para se ter saúde como a alimentação, moradia, meio ambiente, lazer e o acesso aos bens e serviços essenciais $^{12}$.

Parece-nos que embora de forma tímida, diversos homens deste estudo, já compreendem que a saúde depende de vários fatores e não está centrada na questão "ausência de doença". Esse entendimento ampliado pode ser em parte, resultado das políticas de promoção e proteção à saúde, desenvolvidas pelas Estratégias de Saúde da Família, no qual nossa população está cadastrada como usuário, pois, indiretamente, o discurso de cuidado e promoção á saúde é levado para o núcleo familiar pelos integrantes que mais participam dos grupos, como idosos, mulheres e crianças, ou mesmo incorporados pelo homem quando acessam os serviços, seja como paciente ou como acompanhante.

Estudo de Couto et al. ${ }^{13}$ realizado em cidades de quatro estados brasileiros destaca o aumento da presença de homens no cotidiano dos serviços de atenção básica pesquisados, homens em diferentes faixas etárias; sozinhos ou acompanhados; como usuários ou acompanhantes; na posição de filho, pai, esposo/companheiro; em participações episódicas ou uso continuado de atividades; enfim, de diversas formas, estão cada vez mais presentes nas unidades de saúde.

Embora para alguns homens do estudo o entendimento de saúde se aproxima do conceito ampliado, percebemos a dificuldade expressa por estes em cuidar de si, participar e se responsabilizar por sua saúde. Os homens revelam maior dificuldade de buscar a assistência em saúde em razão de sua autopercepção de necessidades de cuidados e pela noção de que esta é uma tarefa do feminino. Demandar cuidados de saúde é algo que desmerece sujeitos criados para assistir e prover ${ }^{10}$.

Essa dificuldade aparece evidenciada em vários relatos:

"Preocupo-me com minha saúde, sempre que tenho algo, mas é dificil procurar ajuda". (Sujeito 3, 25 anos). "Me preocupo, mas não me cuido muito" (Sujeito 40, 24 anos). "[...] Acho que se eu tivesse com um problema de pressão ou um colesterol não me sentiria bem e talvez aí buscasse ajuda e cuidaria da saúde, mas como ainda não tive essa preocupação, não corro pro posto". (Sujeito 30, 46 anos) "[...] Quando se está bem, não se cuida, o homem é mais desleixado, tem muita coisa que poderia evitar, mas só quando está doente mesmo que vai buscar ajuda, me preocupo, mas não me cuido" (Sujeito 40, 24 anos).

Couto et al. ${ }^{13}$ resgata que está constantemente na área da saúde o imaginário que associa em um polo, o feminino, ao cuidado à saúde e, no outro, o masculino, ao não-cuidado. Em seu entorno, encontram-se diversas representações e estereótipos relacionados aos gêneros, tais como, homens são mais fortes; o corpo feminino tem particularidades que demandam mais cuidados; mulheres são naturalmente cuidadoras e homens provedores ${ }^{9,14}$. No que tange a questão de prover, os homens associaram o termo saúde a viver bem, independente e trabalhando, o que de certa forma complementa a ideia de sujeito provedor. 
"Para mim saúde é você poder viver bem com ou sem doença, poder caminhar, trabalhar, se divertir, sem se preocupar com limitações". (Sujeito 7). "Viver bem, comer, dormir e trabalhar". (Sujeito 17, 37 anos). "Pra mim saúde é você poder caminhar, ter a autonomia. Não depender de outras pessoas, viver independente, estar de bem com o corpo e fazer seu trabalho, é claro. Homem tem que trabalhar". (Sujeito 37, 22 anos).

Como destaca Veras ${ }^{15}$, o prolongamento da vida é uma aspiração de qualquer sociedade, no entanto, só pode ser considerado como uma real conquista na medida em que se agregue qualidade aos anos adicionais de vida.

Estudo realizado por Figueiredo e Schraiber ${ }^{16} \mathrm{com} 26$ usuários e profissionais homens evidenciou que o sentido que os leva a se afirmarem como sujeitos dignos e de bom caráter funda-se em atitudes e condutas consideradas necessárias para serem reconhecidos detentores de tais valores. Entre tais atitudes, o trabalho assume uma dimensão central, pois permite que os homens "cumpram com suas obrigações". Nesse sentido, o ser identificado como trabalhador confere ao homem uma virtude moral dignificante, afirmando-o perante os outros, proporcionando-lhe reconhecimento social e, a capacidade física é compreendida como o fio condutor que potencializa a capacidade de trabalhar, e, nesse sentido manter-se ativo, trabalhando e, de forma independente, é estar saudável.

\section{CONSIDERAÇÕES FINAIS}

A maioria dessa população masculina demonstrou ter uma visão de saúde pautada nos elementos culturalmente construídos pelo ideário da masculinidade, em que a concepção de saúde está vinculada a negação das fragilidades, vulnerabilidades, reforçando o conceito de ausência de doenças e, para um grupo menor, esse conceito se apresenta de forma contemporânea, ampliado e multidimensional, mediado pelos determinantes e condicionantes de saúde. No primeiro, a saúde, torna-se preocupação do homem apenas mediante intercorrências graves, pois a masculinidade requer que o homem suporte os sofrimentos com bravura. Já para o segundo grupo, parece-nos que há uma mudança de postura, em que a preocupação com a saúde se dá antes da enfermidade surgir, numa perspectiva preventiva. Fica evidenciado um discurso no que tange ao cuidado com a alimentação, prática de atividade física, tempo para o laser e relações de convívio.

No entanto, constata-se a necessidade de se realizar outros estudos voltados para a concepção de saúde de homens usuários da atenção básica, uma vez que, na literatura, esses estudos são praticamente inexistentes, em termos de realidade nacional. Nesse sentido, a discussão aqui desenvolvida constitui-se num estudo exploratório sobre o tema.

\section{REFERÊNCIAS BIBLIOGRÁFICAS}

1 Schwarz E et al. Política de Saúde do Homem. Rev. Saúde Pública [online]. ahead of print, p. 0-0. Epub Dec 11, 2012.

2 Gomes R et al. A atenção básica à saúde do homem sob a ótica do usuário: um estudo qualitativo em três serviços do Rio de Janeiro . Ciênc. saúde coletiva. 2011;16(11):4513-21. 
3 Scliar M. História do conceito de saúde. Physis. 2007; 17(1): 29-41.

4 Ferretti F, Nierotka RP, Silva MR. Concepção de saúde segundo relato de idosos residentes em ambiente urbano. Interface. 2011;15(37):565-72.

5 Dalmolin BB et al. Significados do conceito de saúde na perspectiva de docentes da área da saúde. Esc. Anna Nery. 2011;15(2): 389-94.

6 Brasil. Ministério da Saúde, Secretaria de Atenção à Saúde, Departamento de Ações Programáticas Estratégicas. Política Nacional de Atenção Integral à Saúde do Homem (princípios e diretrizes). Brasília, 2009.

7 Minayo MCS. O desafio do conhecimento: pesquisa qualitativa em saúde. 8. ed. São Paulo: Hucitec; 2004.

8 Nascimento EF, Gomes R. Marcas identitárias masculinas e a saúde de homens jovens. Cad. Saúde Pública. 2008; 24(7):1556-64.

9 Figueiredo WS. Masculinidades e cuidado: diversidade e necessidades de saúde dos homens na atenção primária. Tese (Doutorado em Ciências) - Faculdade de Medicina, Universidade de São Paulo, São Paulo, 2008.

10 Machin R. et al. Concepções de gênero, masculinidade e cuidados em saúde: estudo com profissionais de saúde da atenção primária . Ciênc. saúde coletiva. 2011;16(11): 4503-12.

11 Fontes WD et al. Atenção à saúde do homem: interlocução entre ensino e serviço. Acta Paul. Enferm. 2011;24(3):430-33.

12 Brasil. Lei n.8.080 de 19 de setembro de 1990 e Lei 8082 de 1992. Dispõem sobre as condições para a promoção, proteção e recuperação da saúde, a organização e o funcionamento dos serviços correspondentes e dá outras providências. Diário Oficial da União, Brasilia, 1990.

13 Couto MT et al. O homem na atenção primária à saúde: discutindo (in) visibilidade a partir da perspectiva de gênero. Interface. 2010;(14)33: 257-70.

14 Gomes R, Nascimento EF, Araujo FC. Por que os homens buscam menos os serviços de saúde do que as mulheres? As explicações de homens com baixa escolaridade e homens com ensino superior. Cad. Saúde Pública. 2007; 23(3): 565-74.

15 Veras R. Envelhecimento populacional contemporâneo: demandas, desafios e inovações. Rev Saúde Pública 2009;43(3):548-54.

16 Figueiredo WS, Schraiber LB. Concepções de gênero de homens usuários e profissionais de saúde de serviços de atenção primária e os possíveis impactos na saúde da população masculina, São Paulo, Brasil. Ciênc. saúde coletiva. 2011;16(suppl.1):935-44.

Artigo apresentado em 08/01/14

Artigo aprovado em 10/07/14

Artigo publicado no sistema em 14/09/14 